\title{
Microplastic pollution in seawater and marine organisms across the Tropical Eastern Pacific and Galápagos
}

\author{
Alonzo Alfaro-Núñez ( $\sim$ alonzoalfaro@gmail.com ) \\ Statens Serum Institut https://orcid.org/0000-0002-4050-5041 \\ Diana Astorga \\ Pontificia Universidad Católica del Ecuador
}

\section{Lenin Cáceres-Farías}

Centro de Sanidad Acuicola, Universidad Técnica de Manabí https://orcid.org/0000-0003-4993-0842

\section{Lisandra Bastidas}

Yachay Tech University

\section{Cynthia Soto Villegas}

Yachay Tech University

\section{Kewrin Choez Macay}

Yachay Tech University

Jan H. Christensen

University of Copenhagen

\section{Article}

Keywords: environmental pollution, plastic waste, marine litter, food contamination, statistical modelling and marine currents

Posted Date: October 7th, 2020

DOI: https://doi.org/10.21203/rs.3.rs-83558/v1

License: (c) (1) This work is licensed under a Creative Commons Attribution 4.0 International License. Read Full License

Version of Record: A version of this preprint was published at Scientific Reports on March 19th, 2021. See the published version at https://doi.org/10.1038/s41598-021-85939-3. 


\section{Abstract}

It is not surprising anymore the detection of plastic debris degrading into micro and nanoplastics across all oceanic environments and in marine organisms, which now appears as one of the world's main concerns. To determine the levels of microplastic pollution at sea, water samples were collected across a 4000 km-trajectory in the Tropical Eastern Pacific and the Galápagos archipelago, covering an area of 453,000 square kilometres. Furthermore, 240 specimens of 16 different species of fish, squid, and shrimp, all of human consumption, were collected along the continental coast. Microplastic particles were found in $100 \%$ of the water samples and marine organisms. Microplastic particles from $150-500 \mu \mathrm{m}$ were the most predominant. This is one of the first reports simultaneously detecting and quantifying microplastic particles abundance in the Eastern Tropical Pacific region, the Galápagos archipelago and inside marine organisms.

\section{Introduction}

Plastics of all sizes have become the most dominant form of marine litter and it has been estimated that at least 5.25 trillion plastic particles weighing above 268,000 tons ${ }^{1,2}$, and approximately $4.8-12.7$ million metric tons of plastic are introduced to the oceans annually ${ }^{3}$. The low cost, lightweight, strength and durability of plastics are properties that make them suitable for the manufacture of a wide range of daily use products. Virtually everything is made of plastic nowadays. However, the high demand and inappropriate disposal of plastic materials have led to their dispersion and accumulation into the environment ${ }^{4}$. This counts for the disposal of 15 tons of plastic per minute. Accordingly to current trends, the total plastic produced is estimated to rise by 33 billion tons by 2050 1,5.

The most important sources of plastic pollution in aquatic oceanic environments are coastal cities, ports, shipping activities, coastal landfills and coastal dumping sites ${ }^{6,7}$. Once plastic debris go into the ocean, they break down into microplastics by photolytic, mechanical and biological degradation.

Historically, plastic debris have been reported and documented at higher density in the Northern Hemisphere oceanic basins when compared to the Southern regions ${ }^{8,9}$. The highest concentrations of plastic debris reported until now are found in the central areas of the North Atlantic and North Pacific Oceans ${ }^{10,11}$. However, there is a clear lack of studies in many oceanic basin regions where data on plastic debris remain unknown. Additionally, oceanic circulation models suggest that all five subtropical ocean gyres act as convergent zones by Ekman currents making them the most likely accumulation regions ${ }^{12}$. As surface ocean currents are spatial and temporal variables, the highest concentrations of plastic debris are constantly fluctuating. However, there is limited available data on the sources and dispersion of plastic litter along the Tropical South American coast and the Galápagos archipelago ${ }^{13}$.

Microplastics ingestion has been reported in a wide range of marine organisms from different trophic levels. The increasing scientific evidence that marine organisms of human consumption ingest microplastics directly from the seawater or from lower trophic levels ${ }^{6,14}$, confirms that these microplastic 
particles have infiltrated the marine ecosystem. They either float through the seawater column or sink when they become covered in biofilm, and settle into the sediments ${ }^{5,15}$. Laboratory experiments have showed the potential of microplastics to be transferred via planktonic organisms from one trophic level to a higher level ${ }^{16}$. Accumulation of plastic micro-particles in lower trophic levels could lead to a domino effect in marine food webs ${ }^{17,18}$, affecting ultimately humans as well.

While there is limited data on the Tropical Pacific and around the multiple archipelagos along the Equator, there is no reason to expect that these zones remain unaffected by microplastics pollution. Thus, this study had as a goal the detection and quantification of microplastic in oceanic surface water and in fish and other marine organism of human consumption, and the use of a spatial design interpolation based on marine oceanic currents in order to document its prevalence in this zone of the Pacific.

\section{Materials And Methods}

\section{Sampling and processing of water samples}

A 25 day-expedition took place on-board the Orion vessel in October 2018, sailing across the Tropical Eastern Pacific and Galápagos archipelago covering an approximated area of 453,000 square-kilometres. The $4000 \mathrm{~km}$-trajectory with 40 sampling stations and their respective geospatial location points is presented in Supplemental material S1. Related to Fig. 1. Environmental water samples were collected under permit \# MAE-DNB-CM-2016-0045 in collaboration with the National Institute of Biodiversity granted by the local Ecuadorian Ministry of Environment.

In order to collect the oceanic water samples, two plankton nets with a $60 \mathrm{~cm}$-diameter, $3 \mathrm{~m}$-length, and $150 \mu \mathrm{m}$ - and $500 \mu \mathrm{m}$ pore size, respectively, were used. Both nets were simultaneously launched at a distance of $30 \mathrm{~m}$ from the stern of the ship in order to prevent any oil or litter contamination from the main vessel. The nets were superficially dragged for a period of 5 minutes at each station, with a speed of 2 knots $(3.70 \mathrm{~km} / \mathrm{h})$. A rough calculation using the volume flow rate formula $\left(Q=\left[A^{\star} s\right]^{\star t}\right.$; where $Q=$ volume flow rate, $A=$ area, $s=$ speed or velocity, and $t=$ dragging time) allows estimating that, on average, at least 550,000 litres of seawater were filtrated at each station. Then, the nets were picked up using a pot line hauler and washed employing a high-pressure seawater hose to collect all organic and inorganic matter into the top end of each net. Later, the content of the top end was transferred to a 500 $\mathrm{mL}$ glass flask, preserved in $70 \%$ ethanol and stored for further analysis. At each station, $500 \mathrm{~mL}$ water control samples were taken from the tube hose to confirm this was not a potential source of microplastic particles contamination.

Between stations, the nets were thoroughly rinsed with ultrapure water to get rid of any residues and were let to dry to guarantee and avoid cross-contamination between samples. Back in the lab, the samples were sifted, using distilled water, into a filtration system consisting of a Glenammer sediment testing set $(5000,1000,750,500$ and $150 \mu \mathrm{m})$. All the organic and inorganic particles that were trapped in test sieves were inspected and separated. Microplastic particles were classified into category sizes. Four 
categories for the $150 \mu \mathrm{m}$-plankton net: 150 - 500, 501 - 750, 751 - 1000 and 1001-5000 $\mu \mathrm{m}$; and three categories for the $500 \mu \mathrm{m}$-plankton net: $500-750,751$ - 1000, and $1001-5000 \mu \mathrm{m}$, which were counted under a stereomicroscope. Organic particles were kept separately for further inspection of ictioplancton and copeds. All remaining organic and inorganic material after the last filtration with the lowest diameter test sieve $(150 \mu \mathrm{m})$ were treated with $30 \%$-hydrogen peroxide to get rid of organic matter ${ }^{19}$, and were then further filtered in a vacuum system employing $100 \mu \mathrm{m}$ microcellulose filters (WhatmanTM). The remaining water was stored in cold at $4^{\circ} \mathrm{C}$ for any future potential analysis with more sensitive and precise technology into nanoparticles. The entire system was rinsed with ultrapure water and $70 \%$ ethanol between each sample filtration to avoid cross-contamination. Extreme care was taken to not contaminate the samples by keeping the filtration system covered and washing the transfer apparatus with ultrapure water and $70 \%$ ethanol multiple times. All washing and purification solutions were filtered through to minimize any sample loss due to adhesion of microplastics on the wall of any part of the filter apparatus. The microplastic isolation was repeated three times for each sample to ensure recovery.

The microcellulose filters were inspected in an AmScope® stereoscope and visual counting of microplastic particles and fibres was done using millimetric background glass filter especially designed for this purpose (Petroff-Hausser counters). Filters were then inspected and microplastic particles counting was done using a BX53 Olympus ${ }^{\circledR}$ microscope. Presence of the microplastic fibres and particles were confirmed by UV-light (see Fig. 2).

\section{Sampling and processing of fish and marine organisms}

To analyse plastic presence in marine organisms of human consumption, 15 specimens of each of the 16 different species collected, including molluscs, fishes and crustaceans, were bought across the most representative market ports in all four provinces (El Oro, Santa Elena, Manabí and Esmeraldas) evaluated in the Pacific coast of Ecuador (see S1), under the same permit mentioned above. They were preserved frozen at $-20^{\circ} \mathrm{C}$. Samples were then dissected and tissue from the digestive tract and the dorsal muscle were investigated for each specimen. The collected samples were analysed in a BX53 Olympus ${ }^{\circledR}$ microscope coupled with a microscale to visually quantify the presence of microplastic particles over 200 $\mu \mathrm{m}$.

For muscle inspection, $0.5 \mathrm{~cm}^{3}$-muscle tissue fragments were imbibed in paraffin. These preparations were tanned with hematoxylin and eosin $(\mathrm{H}-\mathrm{E})$ technique and cut with a microtome ${ }^{20}$. Tissue slices were then prepared on microscope plates using Entellan $\circledast$ resin and inspected for microplastic presence under the BX53 Olympus ${ }^{\circledR}$ microscope.

\section{Quantification, Statistical Analysis and Spatial Interpolations}

Microplastic particles were quantified and total values were determined using counting chambers of 0.2 $\mathrm{mm} \times 0.2 \mathrm{~mm}$ centre square cover glass (Petroff-Hausser counters). Data was tabulated including the exact location of each sampling site, date and the total number of microplastic particles per station with 
each individual net, and by combining the total amounts from both 150 and $500 \mu \mathrm{m}$-plankton nets. Data was then exported to Minitab 18.1.0.0 Statistical Software where the one-way analysis of variance (ANOVA) was performed to obtain descriptive statistics (measures of central tendency and dispersion) for the different groupings as well as for the total sample. The mean differences in the groups were evaluated with Fisher's LSD method with a 95\% confidence interval.

In order to assess the extent of contamination, microplastics presence and distribution were characterized for the selected sampling sites across the Tropical Eastern Pacific and around Galápagos archipelago. This region was divided into four sub-regional zones: Continental waters, International waters, and Eastern and Western Galápagos, within the total of 40 sampled stations. An ANOVA analysis was done to evaluate plastic particles counts in the water in relation to geographical location. A spatial interpolation analysis was performed in ArcGIS 10.4.1 software for the collected microplastics data with combined values for the two nets. Two tools: the Topo to Raster and the Create Contours tools were mainly used. The Topo to Raster tool available in ArcGIS was used as the interpolation method. A study area around the microplastic sampling locations was defined and used as boundary for the interpolation. The Create Contours tool was then used to create 10-units $(\mu \mathrm{p} / \mathrm{ml})$ contours from the raster image produced by the interpolation tool. The tool built isolines that connected points of equal magnitude to produce a shape file.

Global ocean-surface currents vectors are being displayed on the web page of the Jet Propulsion Laboratory of the California Institute of Technology through the State of the Ocean (SOTO) viewer and as animation through Earth NullSchool site. Data correspond to the Ocean Surface Currents Analysis RealTime (SCAR) products from the Earth \& Space Research Institute (ERS). These are 1/3-degree grids, 5-day resolution near-surface total ocean currents estimates. An animation was made using Filmora 9 software. Points of control were used to reference and fit the interpolation graph on top of the animation. Given the 5-day resolution of the ocean currents data set, five shots were used to build a semicontinuous animation.

\section{Results}

\section{Seawater samples}

Microplastic particles were detected in $100 \%$ of the collected samples from the 40 stations across the $4,000 \mathrm{~km}$ trajectory expedition (see Supplemental material S2. Related to Fig. 1). Microplastics prevalence was determined quantitatively according to their size range of four and three category sizes, respectively, according to the sampling net used in each case $(150-500,501-750,751-1000$, and $1001-5000 \mu \mathrm{m}$; determined by the two plankton net sizes). Microplastic particles in all these size ranges were observed in $100 \%$ of the filtered samples analysed.

The highest prevalence by particles size collected with the $150 \mu \mathrm{m}$-plankton net was observed for the smallest category $(150-500 \mu \mathrm{m})$, which concentrated $71 \%$ of particles with an average of $81.43 \pm 29.07$ (mean \pm s.d.) particles per station, with a highly significant difference $(p<0.000)$ with the other four size 
ranges (see S2). The second highest microplastic amount was found in the category of $501-750 \mu \mathrm{m}$, with $15 \%$ and a particle per station mean of $17.45 \pm 8.37$. The third range of particles $751-1000 \mu \mathrm{m}$ was presented at $6 \%$ with a mean per station $7.33 \pm 3.30$. The largest particle size range $(1001-5000 \mu \mathrm{m})$ was the least frequent with an overall $8 \%$ and an average of $9.20 \pm 4.42$ particles per station.

As for the second $500 \mu \mathrm{m}$-plankton net, the highest prevalence by particle size was also observed for the smallest category $(500-750 \mu \mathrm{m})$ in its class, which concentrated $45 \%$ of the particles with an average of $15.00 \pm 7.36$ (mean \pm s.d.) particles per station. The second highest amount of microplastics was found in the $751-1000 \mu \mathrm{m}$ category, with $22 \%$ and a mean number of particles per station of $7.28 \pm 3.55$. The largest particle size range $(1000-5000 \mu \mathrm{m})$ presented a $33 \%$ prevalence and an average of $10.75 \pm 4.60$ particles per station. Furthermore, a high significant difference was detected between the three categories $(p<0.000)$, confirming the vast amount of microplastic particles detected in the size $500-750 \mu \mathrm{m}$ when compared with the other two larger sizes (see S2).

Data analysis revealed that the abundance of plastic particles is strongly correlated to the geographical location. Plastic abundance was quantified by zones, continental waters stations had $116.40 \pm 34.42$, international waters stations $149.50 \pm 40.57$, while $100.80 \pm 36.46$ and $94.90 \pm 33.11$ were registered for Eastern and Western Galápagos stations, respectively. The one-way ANOVA test (see Supplemental material S3. Related to Fig. 1) revealed a statistically significant difference between the four sub-regional zones $(p<0.01)$.

Microplastics appeared mostly in the form of plastic fibres (see Fig. 2), which were found in all collected samples. The largest amount of microplastic particles was found in international waters with the highest value of 428 plastic pieces (combined two net values) at the station 20 (see Supplemental material S4. Related to Fig. 1).

\section{Fish and marine organisms}

A total of 16 species were analysed and clustered by their feeding behaviour, finding the highest microplastic prevalence in carnivorous species, while animals that feed from dead organic matter (detritivore species) were found with the lowest (see Fig. 3). We investigated microplastic particles in the digestive tracts and muscle tissue of 240 marine organisms of human consumption including fishes (210 specimens: 15 of each of 14 species), cephalopod molluscs ( 15 specimens of one species) and crustaceans (15 specimens of one species). Plastic fragments over $200 \mu \mathrm{m}$ were detected in the digestive tract of 166 out of 240 specimens (69\%) from the 16 different species analysed. Microplastics were found in 149 (71\%) of 210 fishes from the 14 different species (see Fig. 3). In overall, $77 \%$ of the carnivorous species presented microplastic pieces in their digestive tract, followed by planktivorous (63\%) and detritivore (20\%). No plastic was found in muscle tissues.

\section{Spatial Interpolations}


Fig. 1 and 4 show the spatial interpolation where, by using the known number of microplastic particles accounted for the combined net values, with the precise oceanic coordinates (stations), estimated values were determined at the remaining unknown points. The result is an interpolation-contours figure showing a possible scenario of the spatial distribution of the microplastics sampled in the studied area. We assumed that for any microplastic particles measured, their magnitude should be equal or greater than zero $(\mu \mathrm{p} / \mathrm{ml})$. The assumption was used to condition the limits of the interpolation method, so the produced raster image contains only numbers equal to or greater than zero.

The graph indicates that the regions in the Southeast ( $82^{\circ}$ longitude) and Northwest ( $92^{\circ}$ longitude) presented the lowest microplastics concentration, with the addition of small region in between islands (stations E24 - E25), which were coloured in blue. The highest microplastic concentration was observed in international waters in the central to southern part of the study area, visually highlighted in reddish colours (see Fig. 1).

\section{Discussion}

\section{Microplastic particles in ocean water}

Worldwide, the spread of plastic debris has been documented through all oceanic ecosystems. Plastic pollution in the oceans is directly correlated with this material being flexible, strong and durable, which is linked to the high amounts of plastics produced, used and easily discarded ${ }^{2,21}$. Microplastic fragments have been found in sedimentary habitats, shores, pelagic zones ${ }^{1,22}$, deep sea ${ }^{23}$ and in living organisms 24 , including humans ${ }^{14}$.

In our study, microplastic particles in the four range sizes $(150-500,501-750,751-1000$ and $1001-$ $5000 \mu \mathrm{m}$ ) were present at all stations (see Figure S1). The size distribution of plastic particles in the seawater samples showed that the smallest size class, between $150-500 \mu \mathrm{m}$, is more abundant than the larger sizes. Other authors have also reported that smaller microplastic sizes abundance is a common characteristic result of the plastic size distribution among the oceans ${ }^{25,26}$. In addition, several studies on microplastic size abundance and distribution have shown a permanent fragmentation of microplastic from larger to smaller, to even into nanoplastic $(<25 \mu \mathrm{m})$, occurring continuously in the oceans ${ }^{6}$, and in all aquatic environments ${ }^{15}$.The main global concern about the predominance of this size class is its risk potential for filter feeders, which tend to confuse it for plankton and end up consuming plastic debris ${ }^{14}$. Further analytical chemistry characterization of the type polymers and POP's present in the samples at each station, was originally intended in this study to cover the smaller fraction and nanoplastic molecular classification. Nevertheless, and as stated below, oil contamination unable this analysis to be achieved.

\section{Modelling of microplastic circulation}

Oceanic circulation models suggest the highest concentrations of plastic debris are accumulated along the five main subtropical ocean gyres defined as convergent zones by the Ekman currents ${ }^{8,27}$. As such, 
ocean currents play a major role in the origin source, transportation, distribution and accumulation of plastic debris around the world. In our study area, several station points were detected with large concentrations of microplastic particles mostly in the central to southern part of the study area, which were outside the local small gyres present (see Fig. 4). These findings are coherent with basin-scale microplastic particles transport that explain sources and pathways of microplastic that end up in the Galápagos Archipelago ${ }^{13}$ from far South oceanic basins. However, Costa Rica and other countries farther north can be considered as plastic particle origin sources if simulations are not limited to surface currents.

Plastic transport may also depend on the sinking processes that plastic particles undergo when they reach the ocean ${ }^{5,11}$. Microplastics present differential buoyancy according to plastic polymers and additives combined for reaching properties of the objects they came from ${ }^{28}$. Around $60 \%$ of plastic items produced are less dense than seawater ${ }^{3}$. Biofouling and other interactions with marine biota, degradation, fragmentation or additives leaching may accelerate the sinking process of derived plastic particles ${ }^{13}$. The impact of microplastics in the marine environments, however, depends on physical behaviors (migration, sedimentation and accumulation), chemical behaviors (degradation and adsorption) and biobehaviors (ingestion, translocation and biodegradation) ${ }^{29}$. Still, trawl sampling efforts coupled with vessel-based sighting surveys confirm that available data on quantities and characteristics of buoyant plastic particles in the nanoplastic range represent only $13 \%$ of the available buoyant plastic mass ${ }^{2}$. Therefore, new insights have coupled measured concentrations of ocean plastic of different sizes and types, dispersal models, geo-referenced imaginary and seasonal and intern annual changes to improve the estimations of plastic debris in the upper water column ${ }^{1}$.

The Galápagos archipelago and its Marine Reserve lay $1000 \mathrm{~km}$ off the coast of the South American coastline and are among the most emblematic wildlife refuges in the world. However, plastic litter and microplastic residues have recently been found even in this isolate group of islands and around its waters. To our knowledge, prior to this study, the levels of this microplastic contamination and its quantification on Galápagos coastlines and across the Eastern Tropical Pacific were barely known and limited to one single study ${ }^{13}$.

\section{Microplastic in marine organism of human consumption}

Plastic particles in the digestive systems of many species of fish and other marine organisms consumable by humans have been reported and quantified ${ }^{17,30}$. Recent studies on plastic size abundance and distribution have shown a continuous fragmentation of microplastic into nanoplastic occurring constantly in the oceans by marine organisms ingesting microplastics and bio-accumulating these particles in their stomachs ${ }^{3,4}$.

In the present study, microplastic contamination and consumption by marine organisms were reported through the quantification of microplastic particles in the digestive tract of 240 marine organisms of human consumption including fishes, cephalopod molluscs and crustaceans. Microplastic fragments 
were detected in 166 out of 240 specimens (69\%) from the 16 different species analysed. Moreover, microplastic particles were found in 149 (71\%) of 210 fish from 14 different species (in at least eight specimens for each of all fish species analysed). This value is higher than those previously reported ${ }^{31}$, which allows to conclude that microplastic debris in the form of fish feed, may accumulate over time and space.

Among all different species analysed in this work, $77 \%$ of the carnivorous species presented microplastic pieces in their digestive tract, followed by planktivorous (63\%) and detritivores (20\%). As previously stated, contamination of microplastic particles of all sizes in the Oceans are easily mistaken with food by marine organisms, especially when they overlap with the size range of their prey ${ }^{7}$. From the total 16 examined species, Dosidicus gigas, commonly known as giant squid, reached $93 \%$ microplastic prevalence in its digestive tract. It was followed by Alopias pelagicus and Coryphaena hippurus with $87 \%$ prevalence each. All three are carnivorous species (see Fig. 3). In a previous study, plastic ingestion in carnivorous species of fish ${ }^{30}$ ranged from $<1 \%$ to $58 \%$. The $77 \%$ obtained in our research breaks the normal parameters, showing that tropical Pacific Equator coast has worrying high levels of microplastic pollution in comparison with reports from other Pacific oceanic basins.

On the other hand, planktivorous species are thought to develop mechanisms to avoid consuming microplastic particles ${ }^{32,33}$. It has been suggested that planktivorous fish species may have a low risk of plastic ingestion in superficial waters ${ }^{10}$. Yet, the $63 \%$ prevalence in planktivorous fish analysed in the present work is considerably high when compared to the $5 \%$ prevalence found from a previous study ${ }^{9}$.

In spite of scientific evidence of plastic entrance to different tissues than those related to the digestive tract 28,34 , no plastic was found in the muscle tissue from the 240 marine organisms examined in this study. This may be due to particle size range analysed, which was limited to microplastic $>150 \mu \mathrm{m}$, and the nanometre range has proven to have greater capacity for tissue translocation ${ }^{4,35}$. As briefly mentioned above, our research originally planned to do an analytical chemistry characterization of the type polymers and POP's present in the samples at each station. Special filter samples were simultaneously collected at each station for this purpose. However, oil contamination was detected in all analysed samples in the lab, which unable to achieve this complementary part of the study and thus, this entire section was excluded from the manuscript. As of today, the cause of the oil contamination remains unknow.

To the best of our knowledge, this is one of the first report quantifying microplastic abundance and circulation in the Tropical Eastern Pacific and around the Galápagos archipelago. This is the first time that microplastic particles are detected and quantified in marine organisms of human consumption in the region.

\section{Declarations}


Alonzo Alfaro-Núñez: Conceptualization, Methodology, Investigation, Data Curation, Writing - Original Draft, Visualization, Supervision, Project Administration and Funding Acquisition. Diana Astorga: Conceptualization, Writing - Review \& Editing, Project Administration and Funding Acquisition. Lenin Cáceres-Farías, Lisandra Bastidas, Cynthia Soto Villegas and Kewrin Choez Macay: Software, Formal analysis and Validation. Jan Christensen: Resources, Writing - Review \& Editing.

\section{Declaration of interests}

The authors declare that they have no known competing financial interests or personal relationships that could have appeared to influence the work reported in this paper.

\section{Funding}

This research study was supported by the Red CEDIA [grant number CEPRA XII-02-18, MICROPLASTICOS].

\section{References}

1. Barnes, D. K. A., Galgani, F., Thompson, R. C. \& Barlaz, M. Accumulation and fragmentation of plastic debris in global environments. Philosophical Transactions of the Royal Society B: Biological Sciences 364, 1985-1998 (2009).

2. Eriksen, M. et al. Plastic Pollution in the World's Oceans: More than 5 Trillion Plastic Pieces Weighing over 250,000 Tons Afloat at Sea. PLOS ONE 9, e111913 (2014).

3. Haward, M. Plastic pollution of the world's seas and oceans as a contemporary challenge in ocean governance. Nat Comms 9, 9994 (2018).

4. Teuten, E. L. et al. Transport and release of chemicals from plastics to the environment and to wildlife. Philosophical Transactions of the Royal Society B: Biological Sciences 364, 2027-2045 (2009).

5. Watson, R. A. et al. Marine foods sourced from farther as their use of global ocean primary production increases. Nat Comms 6, 795 (2015).

6. Tanaka, K. \& Takada, H. Microplastic fragments and microbeads in digestive tracts of planktivorous fish from urban coastal waters. Sci. Rep. 6, 768 (2016).

7. Galloway, T. S., Cole, M. \& Lewis, C. Interactions of microplastic debris throughout the marine ecosystem. Nature Ecology \& Evolution 2016 1:1 1, 1240 (2017).

8. Law, K. L. et al. Plastic Accumulation in the North Atlantic Subtropical Gyre. Science 329, 1185-1188 (2010).

9. Ory, N. et al. Low prevalence of microplastic contamination in planktivorous fish species from the southeast Pacific Ocean. Mar. Pollut. Bull. 127, 211-216 (2018).

10. Law, K. L. et al. Distribution of Surface Plastic Debris in the Eastern Pacific Ocean from an 11-Year Data Set. Environmental Science \& Technology (2014). doi:10.1021/es4053076 
11. Kooi, M., van Nes, E. H., Scheffer, M. \& Koelmans, A. A. Ups and Downs in the Ocean: Effects of Biofouling on Vertical Transport of Microplastics. Environmental Science \& Tecnology 51, 79637971 (2017).

12. Lusher, A. Microplastics in the Marine Environment: Distribution, Interactions and Effects. link.springer.com 245-307 (2015). doi:10.1007/978-3-319-16510-3_10

13. van Sebille, E. et al. Basin-scale sources and pathways of microplastic that ends up in the Galápagos Archipelago. Ocean Science 15, 1341-1349 (2019).

14. Barboza, L. G. A., Vethaak, A. D., Lavorante, B. R. B. O., Lundeye, A.-K. \& Guilhermino, L. Marine microplastic debris: An emerging issue for food security, food safety and human health. Mar. Pollut. Bull. 133, 336-348 (2018).

15. Cole, M. et al. Isolation of microplastics in biota-rich seawater samples and marine organisms. Sci. Rep. 4, 4528 (2014).

16. Cózar, A. et al. Plastic debris in the open ocean. Proceedings of the National Academy of Sciences 111, 10239-10244 (2014).

17. Bouwmeester, H., Hollman, P. C. H. \& Peters, R. J. B. Potential Health Impact of Environmentally Released Micro- and Nanoplastics in the Human Food Production Chain: Experiences from Nanotoxicology. Environmental Science \& Technology 49, 8932-8947 (2015).

18. Rochman, C. M. et al. Classify plastic waste as hazardous. Nature 494, 169-171 (2013).

19. Jensen, J. L., Schjønning, P., Watts, C. W., Christensen, B. T. \& Munkholm, L. J. Soil texture analysis revisited: Removal of organic matter matters more than ever. PLOS ONE 12, e0178039 (2017).

20. Fischer, A. H., Jacobson, K. A., Rose, J. \& Zeller, R. Hematoxylin and eosin staining of tissue and cell sections. CSH Protoc 2008, pdb.prot4986 (2008).

21. Alonzo, A.-N., Section for Evolutionary Genomics, Centre for GeoGenetics, Natural History Museum of Denmark, University of Copenhagen, Copenhagen1350, Denmark, Bermúdez, R., ESPOL Polytechnic University, Escuela Superior Politécnica del Litoral, ESPOL, Plankton Laboratory, Facultad de Ingenería Marítima, Ciencias Biológicas, Oceánicas y Recursos Naturales, Campus Gustavo Galindo, Guayaquil, EcuadorGalapagos Marine Research and Exploration, GMaRE. Joint ESPOL-CDF program, Charles Darwin Research Station, Galapagos Islands, Ecuador. The scientific problem of plastic pollution: an ocean of reports with little standardization of procedures. $R B \mathbf{3},(2018)$.

22. Thompson, R. C. et al. Lost at Sea: Where Is All the Plastic? Science 304, 838-838 (2004).

23. Galgani, F., Souplet, A. \& Cadiou, Y. Accumulation of debris on the deep sea floor off the French Mediterranean coast. Mar. Ecol. Prog. Ser. 142, 225-234 (1996).

24. Long, M. et al. Interactions between polystyrene microplastics and marine phytoplankton lead to species-specific hetero-aggregation. Environmental Pollution 228, 454-463 (2017).

25. Hidalgo-Ruz, V., Gutow, L., Thompson, R. C. \& Thiel, M. Microplastics in the Marine Environment: A Review of the Methods Used for Identification and Quantification. Environmental Science \& Technology 46, 3060-3075 (2012). 
26. Engler, R. E. The Complex Interaction between Marine Debris and Toxic Chemicals in the Ocean. Environmental Science \& Technology 46, 12302-12315 (2012).

27. Eriksen, M. et al. Plastic pollution in the South Pacific subtropical gyre. Mar. Pollut. Bull. 68, 71-76 (2013).

28. Avio, C. G. et al. Pollutants bioavailability and toxicological risk from microplastics to marine mussels. Environmental Pollution 198, 211-222 (2015).

29. Wang, W., Gao, H., Jin, S., Li, R. \& Na, G. The ecotoxicological effects of microplastics on aquatic food web, from primary producer to human: A review. Ecotoxicology and Environmental Safety 173, 110-117 (2019).

30. Miranda, D. de A. \& Carvalho-Souza, G. F. de. Are we eating plastic-ingesting fish? Mar. Pollut. Bull. 103, 109-114 (2016).

31. Neves, D., Sobral, P., Ferreira, J. L. \& Pereira, T. Ingestion of microplastics by commercial fish off the Portuguese coast. Mar. Pollut. Bull. 101, 119-126 (2015).

32. Kaposi, K. L., Mos, B., Kelaher, B. P. \& Dworjanyn, S. A. Ingestion of Microplastic Has Limited Impact on a Marine Larva. Environmental Science \& Technology (2013). doi:10.1021/es404295e

33. Cole, M. \& Galloway, T. S. Ingestion of Nanoplastics and Microplastics by Pacific Oyster Larvae. Environmental Science \& Technology (2015). doi:10.1021/acs.est.5b04099

34. Moos, von, N., Burkhardt-Holm, P. \& Köhler, A. Uptake and Effects of Microplastics on Cells and Tissue of the Blue Mussel Mytilus edulisL. after an Experimental Exposure. Environmental Science \& Technology 46, 11327-11335 (2012).

35. Lehner, R., Weder, C., Petri-Fink, A. \& Rothen-Rutishauser, B. Emergence of Nanoplastic in the Environment and Possible Impact on Human Health. Environmental Science \& Technology (2019). doi:10.1021/acs.est.8b05512

\section{Figures}




\section{Figure 1}

Spatial microplastic interpolation. Using the known values of microplastic particles, combining both 150 and $500 \mu \mathrm{m}$-plankton nets at the precise oceanic stations, estimate values are determined at the remaining unknown points. The Southeast and Northwest presented the lowest microplastics concentration, which was coloured in blue. The highest microplastic concentration was observed in international waters in the central to southern part of the study area coloured in red, potentially associated with ocean circulation patterns. Note: The designations employed and the presentation of the material on this map do not imply the expression of any opinion whatsoever on the part of Research Square concerning the legal status of any country, territory, city or area or of its authorities, or concerning the delimitation of its frontiers or boundaries. This map has been provided by the authors.

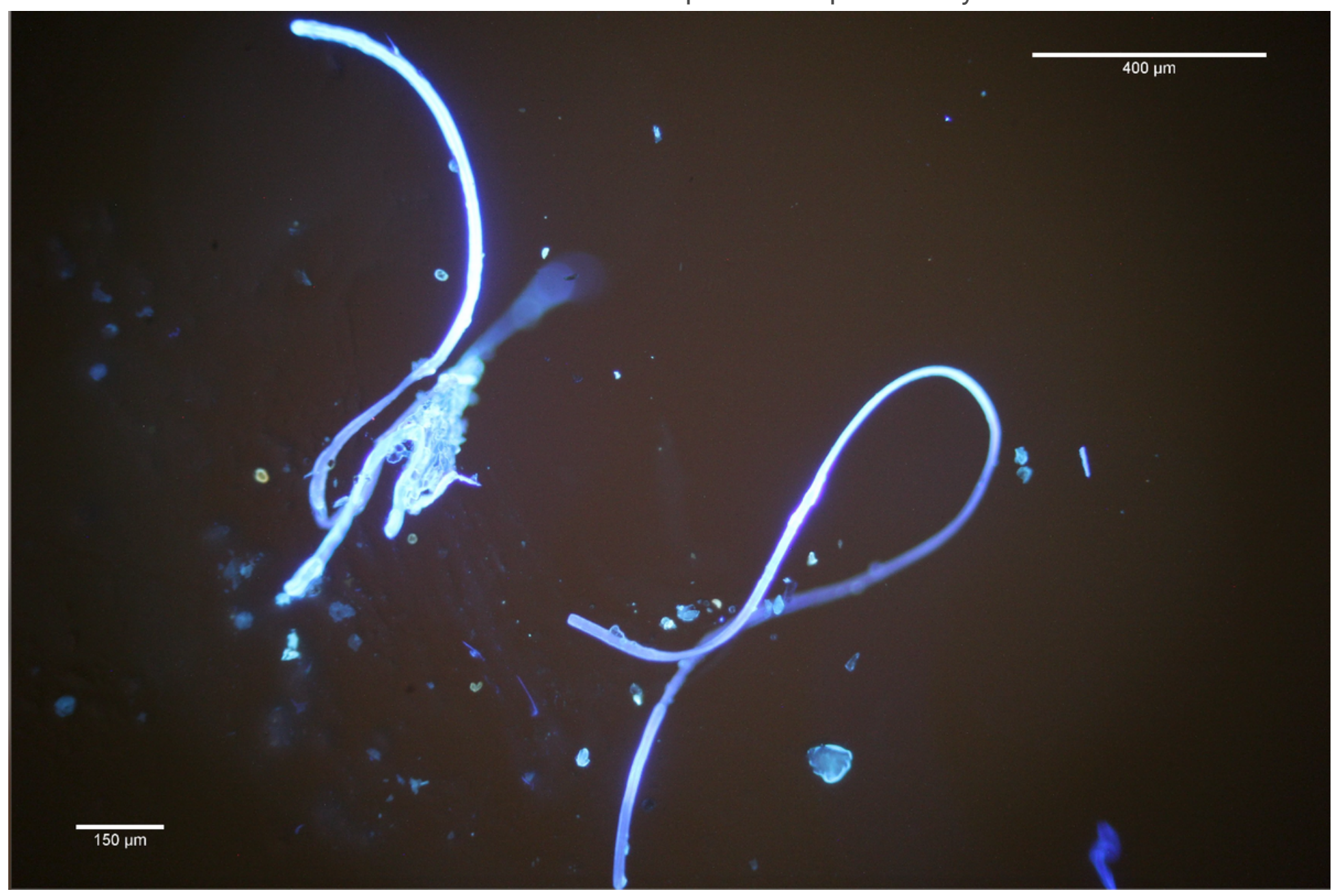

\section{Figure 2}

Microplastic fibres and particles under the microscope. Each of the filters collected was inspected and investigated under the microscope to quantify the amount of microplastic fibres and particles. Most polymers, the main structural molecular blocks of plastics, tend to shine under the ultraviolet light (UVlight), which was done using a BX53 Olympus ${ }^{\circledR}$ microscope. 


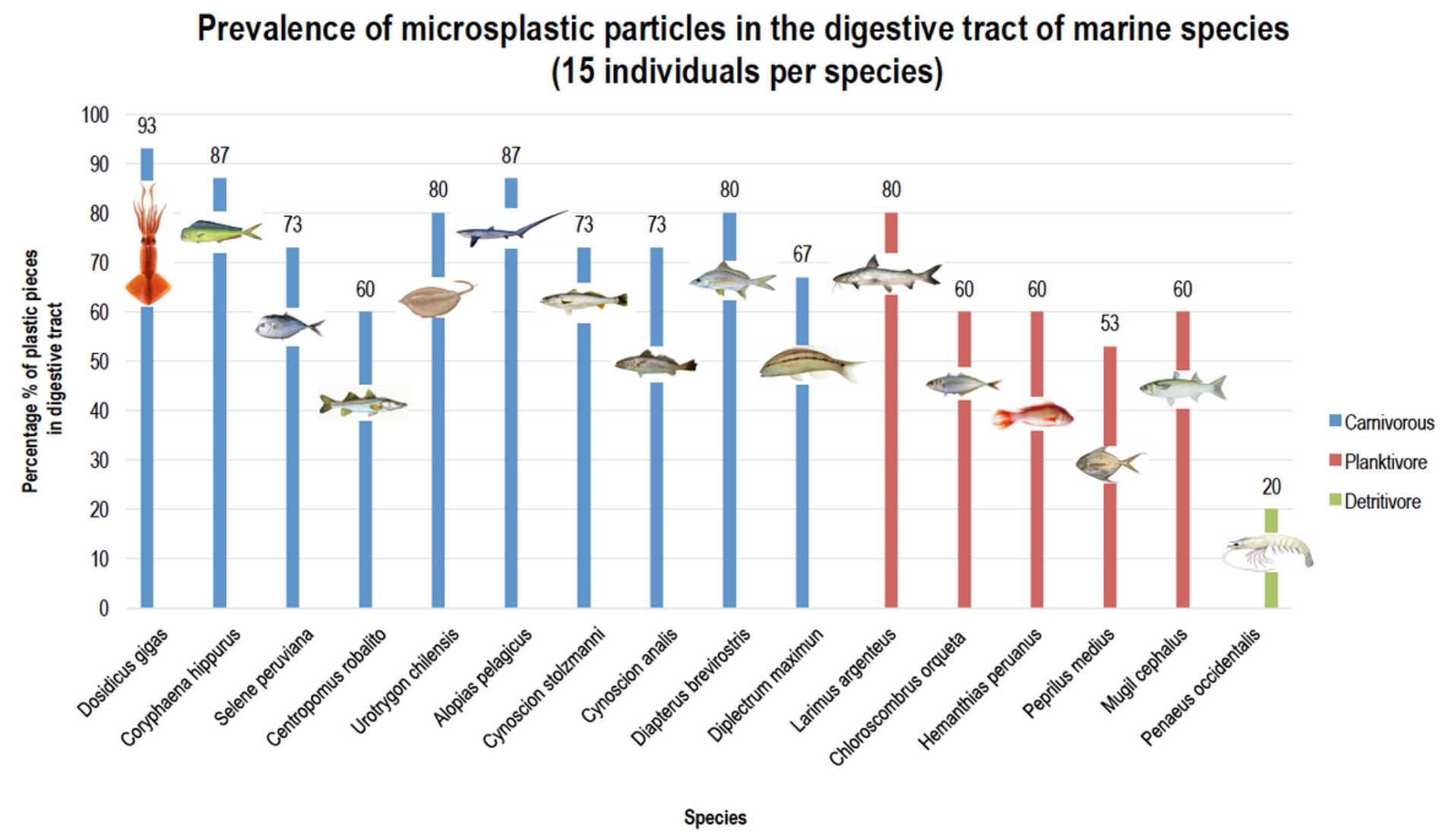

\section{Figure 3}

Prevalence of microplastic particles in the digestive track of marine species. Microplastic particles found in 16 different marine species of human consumption that were bought in the most representative ports in all four provinces (Manabí, El Oro, Esmeraldas and Santa Elena) in the Pacific coast of Ecuador were quantified. Marine organisms were categorized by their feeding behaviour: carnivorous, planktivory, and detritivore. Fifteen specimens $(n=15)$ were taken per each of the 16 species analysed. 
Please see the supplemental files to download and view Figure 4 (video file).

\section{Figure 4}

Animation of microplastic circulation. The animation was made showing isolines based on the interpolation of the data set collected. As sample collection was performed between October 3rd and 27th 2018 , the ocean currents data used for the animation comprise the available data between October 6 th and 26th 2018. The animation shows in the background direction (lines) and speed (colour code: red = fast, blue $=$ slow $)$ of ocean surface currents. The deep blue zones have zero velocities $(\mathrm{km} / \mathrm{h})$ while the reddish zones like those around the Galápagos archipelago reach up to $6.5 \mathrm{~km} / \mathrm{h}$. The colour of the interpolation contours was inverted (compared to Fig. 1), where blue colour represents higher concentration while reddish colours stand for lowest concentrations of microplastics.

\section{Supplementary Files}

This is a list of supplementary files associated with this preprint. Click to download.

- S1.pdf

- S2.MicroplasticparticlesbysizeintheOcean.pdf

- S3.pdf

- S4.pdf

- Fig.4.mp4 